\title{
Improved Efficiency of Miscible C02 Floods and Enhanced Prospects for C02 Flooding Heterogeneous Reservoirs
}

\author{
Quarterly Report \\ July 1 - September 30, 1997
}

By
Reid B. Grigg; David S. Schechter; Shih-Hsien (Eric) Chang
Boyun (Gordon) Guo; Jyun-Syung Tsau

Work Performed Under Contract No.: DE-FG26-97BC15747

\author{
For \\ U.S. Department of Energy \\ Office of Fossil Energy \\ Federal Energy Technology Center \\ P.O. Box 880 \\ Morgantown, West Virginia 26507-0880
}

By

New Mexico Petroleum Recovery Research Center

New Mexico Institute of Mining and Technology

Socorro, New Mexico 87801 


\section{Disclaimer}

This report was prepared as an account of work sponsored by an agency of the United States Government. Neither the United States Government nor any agency thereof, nor any of their employees, makes any warranty, express or implied, or assumes any legal liability or responsibility for the accuracy, completeness, or usefulness of any information, apparatus, product, or process disclosed, or represents that its use would not infringe privately owned rights. Reference herein to any specific commercial product, process, or service by trade

name, trademark, manufacturer, or otherwise does not necessarily constitute or imply its endorsement, recommendation, or favoring by the United States Government or any agency thereof. The views and opinions of authors expressed herein do not necessarily state or reflect those of the United States Government or any agency thereof. 
Quarterly Technical Progress Report

IMPROVED EFFICIENCY OF MISCIBLE C QFLOODS AND ENHANCED PROSPECTS FOR $\mathrm{CO}_{2}$ FLOODING HETEROGENEOUS RESERVOIRS

DOE Contract No. DE-FG26-97BC15747

New Mexico Petroleum Recovery Research Center

New Mexico Institute of Mining and Technology

Socorro, NM 87801

(505) 835-5142

Report Date:

October 31, 1997

Contract Date:

June 1, 1997

Completion Date:

May 31, 2000

DOE Award of $1^{\text {st }}$ year:

$\$ 319,548$

Program Manager:

Reid B. Grigg

Principal Investigators:

Reid B. Grigg

David S. Schechter

Other Major Contributors: Shih-Hsien (Eric) Chang

Boyun (Gordon) Guo

Jyun-Syung Tsau

Contracting Officer's Representative Jerry F. Casteel

Reporting Period:

PRRC Report 97-34

July 1, 1997-September 30, 1997 


\section{DISCLAIMER}

This report was prepared as an account of work sponsored by an agency of the United States Government. Neither the United States Government nor any agency thereof, nor any of their employees, makes any warranty, express or implied, or assumes any legal liability or responsibility for the accuracy, completeness, or usefulness of any information, apparatus, product, or process disclosed, or represents that its use would not infringe privately owned rights. Reference herein to any specific commercial product, process, or service by trade name, trademark, manufacturer, or otherwise does not necessarily constitute or imply its endorsement, recommendation, or favoring by the United States Government or any agency thereof. The views and opinions of authors expressed herein do not necessarily state or reflect those of the United States Government or any agency thereof.

\section{ABSTRACT}

A new grant, "Improved Efficiency of Miscible $\mathrm{CO}_{2}$ Floods and Enhanced Prospects for $\mathrm{CO}_{2}$ Flooding Heterogeneous Reservoirs,” DOE Contract No. DE-FG26-97BC15047, was awarded and started on June 1, 1997. This work will examine three major areas in which $\mathrm{CO}_{2}$ flooding can be improved: fluid and matrix interactions, conformance control/sweep efficiency, and reservoir simulation for improved oil recovery.

The first full quarter of this project has been completed. We began examining synergistic affects of mixed surfactant versus single surfactant systems to enhance the properties of foams used for improving oil recovery in $\mathrm{CO}_{2}$ floods. The purpose is to reduce the concentration of surfactants or finding less expensive surfactants. Also, we are examining the effect of oil saturation on the development of foam in $\mathrm{CO}_{2}$-surfactant solution systems. $\mathrm{CO}_{2}$ flooding of low permeability, vugular, and fracture reservoirs are another major thrust of this project. Work conducted this quarter involved simulating gravity stable floods using large core samples; results showed excellent recovery in a low permeability vugular core. 


\section{EXECUTIVE SUMMARY}

A new grant, "Improved Efficiency of Miscible $\mathrm{CO}_{2}$ Floods and Enhanced Prospects for $\mathrm{CO}_{2}$ Flooding Heterogeneous Reservoirs," DOE Contract No. DE-FG26-97BC15047, was awarded and started on June 1, 1997. This work will examine three major areas in which $\mathrm{CO}_{2}$ flooding can be improved: fluid and matrix interactions, conformance control/sweep efficiency, and reservoir simulation for improved oil recovery.

The first full quarter of this project has been completed. We began examining synergistic affects of mixed surfactant versus single surfactant systems to enhance the properties of foams used for improving oil recovery in $\mathrm{CO}_{2}$ floods. The purpose is to reduce the concentration of surfactants or finding less expensive surfactants. Also, we are examining the effect of oil saturation on the development of foam in $\mathrm{CO}_{2}$-surfactant solution systems. $\mathrm{CO}_{2}$ flooding of low permeability, vugular, and fracture reservoirs are another major thrust of this project. Work conducted this quarter involved simulating gravity stable floods using large core samples; results showed excellent recovery in a low permeability vugular core. 


\section{INTRODUCTION}

Because of the importance of $\mathrm{CO}_{2}$ flooding to future oil recovery in New Mexico, west Texas, and the United States, the Petroleum Recovery Research Center (PRRC) pursues a vigorous research program to improve the effectiveness of $\mathrm{CO}_{2}$ flooding in heterogeneous reservoirs. The results of our research continues to expand the list of viable candidates for $\mathrm{CO}_{2}$ flooding. Our primary interests are to include more low-pressure reservoirs and many more heterogeneous or fractured reservoirs in our research.

Continued support for oil recovery research by $\mathrm{CO}_{2}$ flooding has been provided by the U.S. Department of Energy for an additional three years through a grant entitled: "Improved Efficiency of Miscible $\mathrm{CO}_{2}$ Floods and Enhanced Prospects for $\mathrm{CO}_{2}$ Flooding Heterogeneous Reservoirs." The New Mexico Petroleum Recovery Research Center (PRRC) is well known as a premier institution for improved oil recovery (IOR) research and, in particular, for its research on the use of highpressure $\mathrm{CO}_{2}$ injection. The extension will continue the progress on understanding $\mathrm{CO}_{2}$ flooding in heterogeneous reservoirs, further the development of methods to enable $\mathrm{CO}_{2}$ flooding in more heterogeneous reservoirs, and continue the dissemination of this information to promote successful implementation of these methods. The research will proceed in three related areas:

- Fluid and matrix interactions (understanding the problems): interfacial tension (IFT), phase behavior, development of miscibility, capillary number $(\mathrm{Nc})$, injectivity, wettability, gravity drainage, etc.

- Conformance control/sweep efficiency (solving the problems): reduction of mobility using foam, diversion by selective mobility reduction (SMR) using foam, improved injectivity, WAG, horizontal wells, etc.

- Reservoir simulation for improved oil recovery (predicting results): gravity drainage, SMR, $\mathrm{CO}_{2}$ /foam flooding, IFT, injectivity profile, horizontal wells, and naturally fractured reservoirs.

All areas originate from research on the mechanics of oil recovery by high-pressure $\mathrm{CO}_{2}$. Experience gained during the current project is relevant to our continued efforts. Future research in 
each of the three areas will increase both the quantity of oil produced and the efficiency of oil recovery from $\mathrm{CO}_{2}$ flooding. Special attention will be given to disseminating research results through an extensive technology transfer effort. Because of the importance of $\mathrm{CO}_{2}$ flooding in New Mexico reservoirs, additional funds are being provided through a combination of state and industry funds.

\section{SUMMARY OF TECHNICAL PROGRESS}

\section{Conformance Control/Sweep Efficiency}

Experiments were performed to evaluate properties of mixed surfactants and their effectiveness in stabilizing foam at high pressure using a foam durability apparatus. We examined various mixed surfactant systems, such as alpha olefin sulfonate and ethoxylated alcohol sulfate, at low concentrations (less than $500 \mathrm{ppm}$ ) to determine their foaming ability and the stability of the foam. The test results were used in conjunction with our foam flowing tests to study the potential for using mixed surfactants at low concentration to improve mobility control in $\mathrm{CO}_{2}$ flooding.

Experiments were conducted on a fired Berea sandstone core with $\mathrm{CO}_{2}, \mathrm{CO}_{2}$ /brine, and $\mathrm{CO}_{2}$ foam at different saturations of brine, surfactant solution, and oil. The breakthrough time and increment of fluid recovery were recorded and compared. Without the presence of oil in the core, $\mathrm{CO}_{2}$ breakthrough time increased when the core was initially saturated with the surfactant solution versus brine. The breakthrough of $\mathrm{CO}_{2}$ was delayed further when $\mathrm{CO}_{2}$ and surfactant were coinjected

in the core. When oil was present in the core, the breakthrough time of $\mathrm{CO}_{2}$ was reduced in all comparable cases, but was longest when $\mathrm{CO}_{2}$ was coinjected with surfactant solution. Thus, the presence of oil was found to affect the performance of $\mathrm{CO}_{2}$ and foam during the flooding process.

\section{$\mathrm{CO}_{2}$-ASSISTED GRAVITY DRAINAGE IN A VUGULAR CORE}

Minimum miscibility tests were performed on recombined reservoir fluid from the Wellman Unit. Tests were performed on three samples having solution gas-to-oil-ratios (GOR) ranging from $150 \mathrm{scf} / \mathrm{bbl}$ to $600 \mathrm{scf} / \mathrm{bbl}$. The influence of GOR on the minimum miscibility pressures (MMP) was found to be minimal. The MMP at reservoir temperature of $151^{\circ} \mathrm{F}$ was found to be $1600 \pm 25 \mathrm{psig}$. Increasing the GOR increased the MMP only slightly. 
A core test simulating a gravity drainage $\mathrm{CO}_{2}$ flood was performed using reservoir core and 400 GOR recombined reservoir oil. A 4 inches diameter by 28 inches length of whole core from depth $9403.6 \mathrm{ft}$ - $9406.5 \mathrm{ft}$ from the Wellman Unit was oriented vertically in a core holder. The pore volume (PV) was determined to be 390 cubic centimeters (6.76\% porosity) by brine injection and had a vertical brine permeability of $15.4 \mathrm{md}$.

The following procedure was used to condition the core and simulate an upward waterflood and a downward $\mathrm{CO}_{2}$ flood:

1. $10 \mathrm{PV}$ of brine was injected into the core at $150^{\circ} \mathrm{F}$ and $1900 \mathrm{psig}$.

2. Dead oil was injected into the core and aged ten days at the above temperature and pressure.

3. Separator oil was injected into the core until water saturation was reduced to $23 \%$.

4. Recombined reservoir oil was then injected into the core and aged for three days.

5. Brine was slowly injected into the core from the bottom vertically upwards to simulate a upward water drive in the Wellman reservoir. A total of about 5 PV of brine was injected into the core. The final average water saturation was $53 \%$.

6. $\mathrm{CO}_{2}$ was then injected into the top of the core at a rate of $20 \mathrm{cc}$ per hour. During $\mathrm{CO}_{2}$ injection, the temperature was maintained at $151^{\circ} \mathrm{F}$ and pressure of $1650 \mathrm{psig}$.

Water and oil production from the core during $\mathrm{CO}_{2}$ injection are presented in Figure 1. This figure shows that oil and water were not produced proportionally. For the first $150 \mathrm{cc}$ of $\mathrm{CO}_{2}$ injected, the produced liquid was essentially water alone; thereafter water production decreased and oil production increased rapidly. This result indicates the formation of an oil bank at the $\mathrm{CO}_{2}$ front during a gravity-stable $\mathrm{CO}_{2}$ displacement. Figure 2 shows back-calculated changes in water and oil saturations in the core during $\mathrm{CO}_{2}$ injection. After $0.5 \mathrm{PV}$ of $\mathrm{CO}_{2}$ injection, essentially all of the mobile water was removed from the core with a final water saturation of under $20 \%$. After $1.3 \mathrm{PV}$ of $\mathrm{CO}_{2}$ was injected, residual oil was reduced to about $10 \% \mathrm{PV}$, or a final oil recovery of $79 \%$ OOIP after the water flood. This could represent a gravity-stable $\mathrm{CO}_{2}$ flood after a good water flood or in a water-oil transition zone.

Oil saturation was decreased another $3 \% \mathrm{PV}$ by injecting $\mathrm{CO}_{2}$ to increase the pressure to 1740 psig, followed by a three day $\mathrm{CO}_{2}$ soak at 1740 psig and $156^{\circ} \mathrm{F}$. Then injecting another $0.3 \mathrm{PV}$ of $\mathrm{CO}_{2}$ at a rate of $50 \mathrm{cc}$ per hour with a back pressure of $1650 \mathrm{psig}$, soaking that for another nine days, 
and finally injecting another $4.3 \mathrm{PV}$ of $\mathrm{CO}_{2}$ at high flow rates. After blowdown and flushing the core with methanol and chloroform, all but about $2.5 \% \mathrm{PV}$ of the liquid hydrocarbon was accounted for in produced fluids. The system was then resaturated with brine and the core PV was found to be close to PV determined initially. 


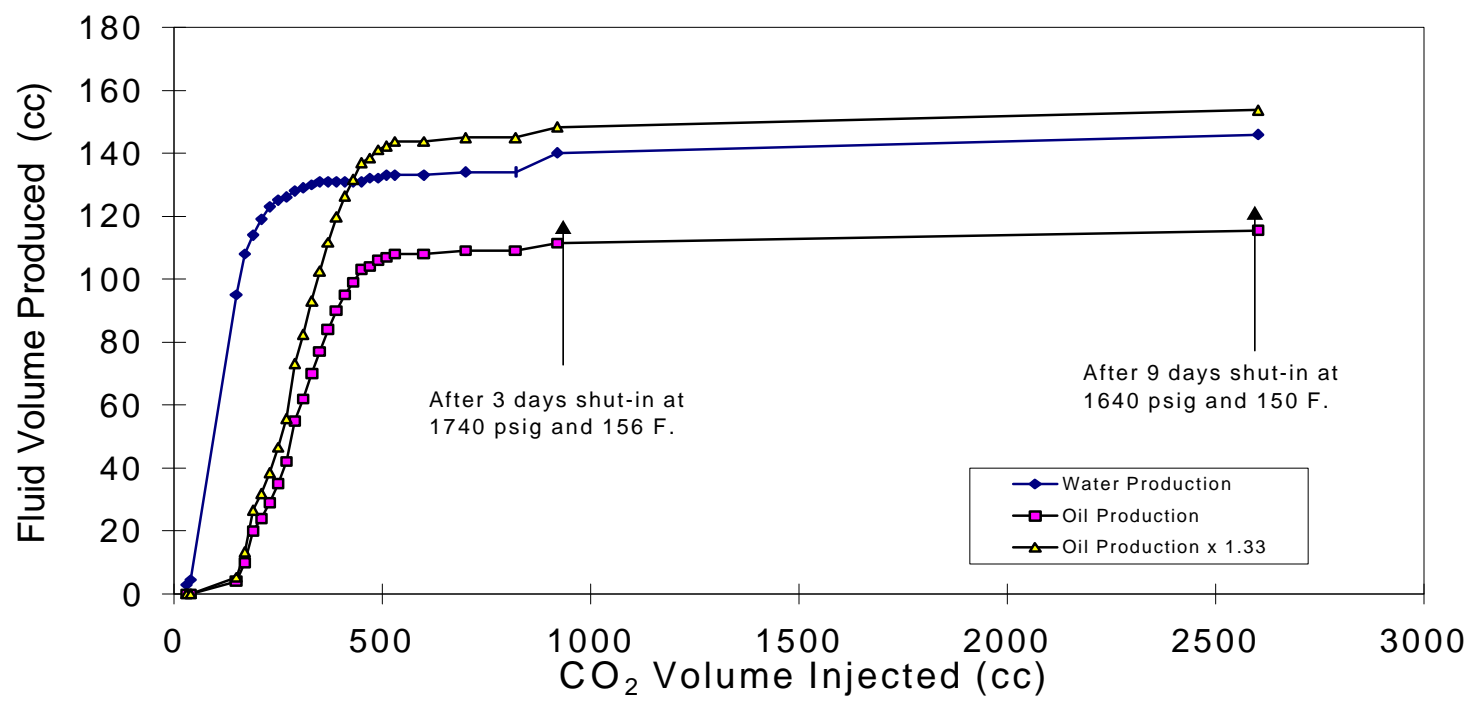

Figure 1, Fluid Production versus $\mathrm{CO}_{2}$ Throughput during $\mathrm{CO}_{2}$ Assisted Gravity Drainage

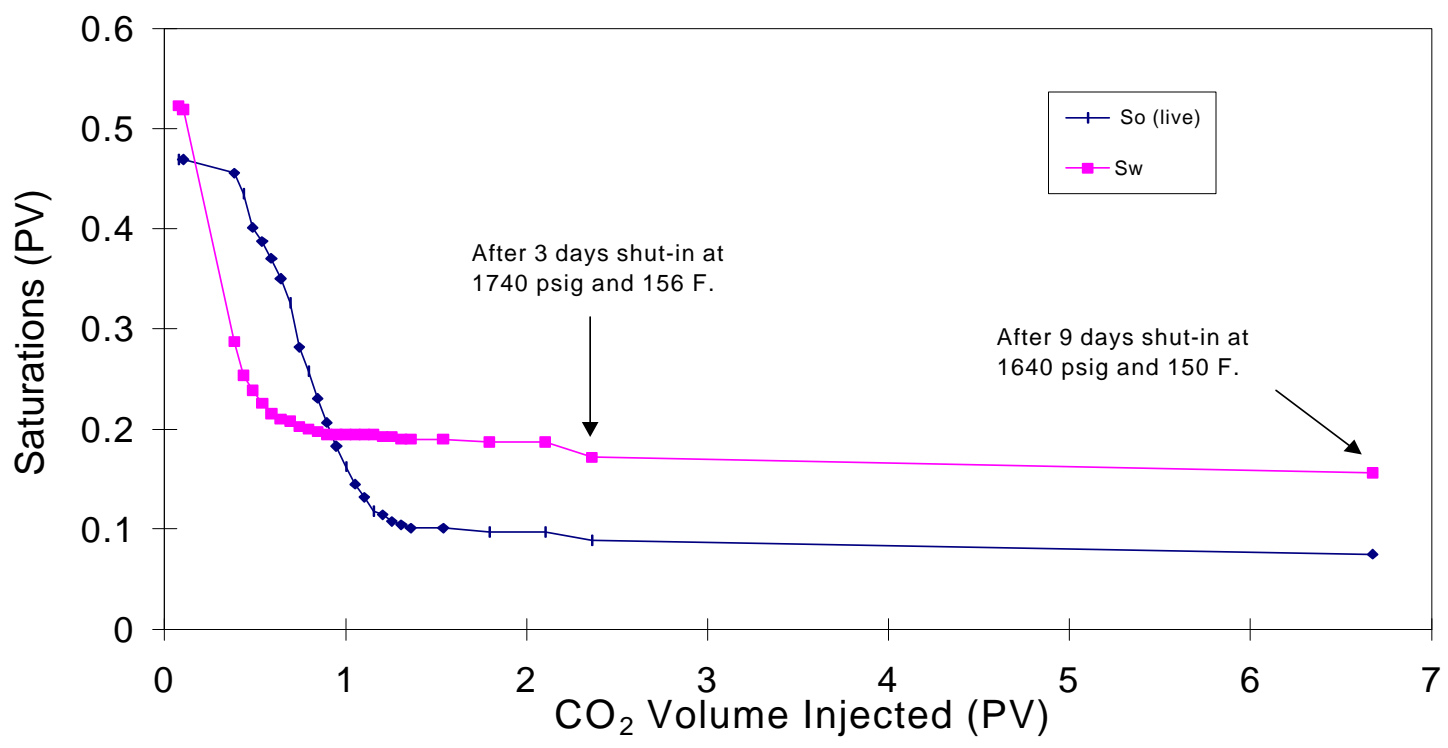

Figure 2, Changes in Fluid Saturations in the Wellman Unit Whole Core during $\mathrm{CO}_{2}$ - Assisted Gravity Drainage 